AWEJ for Translation \& Literary Studies, Volume 4, Number4. October 2020

Pp.17 -34

DOI: http://dx.doi.org/10.24093/awejtls/vol4no4.2

\title{
Narrative Control or Aesthetic Ideal: Cognitive Narrative Reading of Milan Kundera's Life Is Elsewhere
}

\section{Sara Mechraoui}

Independent Researcher, Indianapolis, Indiana, U.S.A

\begin{abstract}
This study, which is inspired by Cognitive Poetics, aims to test the feasibility of its basic methods on the analysis of Milan Kundera's novel Life Is Elsewhere (1973). Kundera's style seems at first plain, but greater importance was given to his philosophical and psychological treatment of subjects than the narratological world that he creates. He brilliantly mixes many narrative techniques to expose his existential and aesthetic ideals. The aesthetic value of the novel studied under the cognitive stylistic approach in this study sought answers to the following question. How can Life Is Elsewhere (1973) be read from a cognitive linguistic perspective? The findings confirmed the relevance of the cognitive poetic approach to the narrow reading of Milan Kundera's works. Life Is Elsewhere (1973) is a merit of narrative control in that the author allows the reader to live the life story of a young poet, to appreciate his ups and downs, at the same time, read his philosophical ideas about life and his artistic control of the novel. Though a cognitively inspired approach might seem odd at the thematic level, for a purely hermeneutic researcher, the level at which both author and reader would exchange meaning from the text is catered for in the rich textual world of the novel. The latter sustains the universality of the works and confirms the suitability of the cognitive poetic framework to any piece of literature.
\end{abstract}

Keywords: mental space theory, cognitive stylistics, text world theory, Life Is Elsewhere, Milan Kundera, aesthetic ideal

Cite as: Mechraoui, S. (2020). Narrative Control or Aesthetic Ideal: Cognitive Narrative Reading of Milan Kundera's Life Is Elsewhere. Arab World English Journal for Translation \& Literary Studies 4 (4) 17 -34. DOI: http://dx.doi.org/10.24093/awejtls/vol4no4.2 


\section{Introduction}

After reading a piece of literature, be it a poem, a short story, or a novel, the reader's mind creates an ongoing interaction with the world of the text. It can be overtly expressed by liking the story or by hating one of the characters. Though literary theories label each with a specific name as tone or mood, the world of interaction remains conceptual. How the reader comes to an understanding of the world of the novel is the target of cognitive poetic research. Blending inputs between the reader's cognitive repertoire and the work of the author through the presented text is the central point of most cognitive research in the literary canon. As elaborated in the abstract, this research study is inspired by the cognitive poetic analysis of Milan Kundra's novel Life Is Elsewhere (1973). Under the umbrella term Cognitive Poetics, many sub approaches converge, their aim is to interpret literary texts as excellently produced by their authors and intelligently communicated by their readers. Unlike other case studies in the cognitive poetic paradigm, novels of straightforward style and counterparts, as in the work of Kundera, need a detailed analysis of every embedded world that is accessible to the reader.

\section{Literature Review}

\section{Cognitive Approaches to Analyzing Fiction}

After the outbreak of neurobiological and cognitive discoveries in the last three decades, schematic and intertextual analyses were utilized in literary studies. Prime of which was done in poetry (Gavins, 2007; Stockwell; 2005, 2009); later it developed into fiction (Mandler, 1984; Schank\& Abelson, 1977; Sternberg, 2003; Cook, 1994; Herman, 2002; Stockwell, 2002; Palmer, 2004). Each trend in a literary analysis or school in a broader sense sets rules to figure out how text affects its reading, how the reader interacts with the text, or how the mental and socio-cultural background affects the reading of the texts. The hermeneutic tradition, which emphasized various and continuing interpretations of the concrete text, was phenomenological. The Structuralists looked for the rules governing narratives, while the empirical studies concentrated on the biological reactions of the readers, i.e., how the real reader responds to the reading text.

Before delving into the cognitive approaches to analyzing fiction, an operational definition of cognitivist, cognitive, and fiction should be given. The term cognitivist concerns the study of the mental operations that the reader undergoes to comprehend narratives. Cognitive, on the other hand, refers to the host of approaches akin to the cognitive turn in studying literature (Bernaerts, De Geest, Herman \& Vervaek, 2013). The title fiction above is intentionally used since it encompasses narrative fiction than other types of narratives. Narrative fiction, as classified by critiques, includes novels, short stories, or narrative poems. Rimon-Kenan (1983-2002) defines narrative fiction as "the narration of a succession of events. An event is something that happens and can be summed up by a verb or a name of an action (2)". She illustrated from the definition of poetics as given by Hrushovski (1976), and clarified the state of narrative fiction vis-a-vis other narratives. Hrushovski's description of poetics reads as follows:

The systematic study of literature as it is. It deals with the question 'what is literature?' and with all possible questions developed from it such as: what is art in language? What are the forms and kinds of literature? What is the nature of one literary genre or trend? What is the 
system of a particular poet's art or language? How is a story made? What are the specific aspects of works of literature? How are they constituted? How do literary texts embody non-literary phenomena? (p. xv)

If a closer look is taken at the above definition, the cognitive aspect of a reading of literature is not delineated though this was written a while before the emergence of the cognitive studies of literature. The words systematic, the what, and the how imply a teleological and inductive approach to the analysis of literature. The school that is strongly associated with the study of the system underlying works of literature is Structuralism. Prominent supporters of Structuralism opted for generalizable and all-encompassing rules that can account for all genres of literature. The what and how that are highlighted in the passage are labels for the story and the discourse in the narrative. Structuralism refers to the story, as the content or chain of events that are part of the work; whereas discourse is the expression; how the content is communicated. Additionally, they clarified the components of the narrative by dividing each into sub-components. Chatman (1978) outlines the parts of narrative into the following:

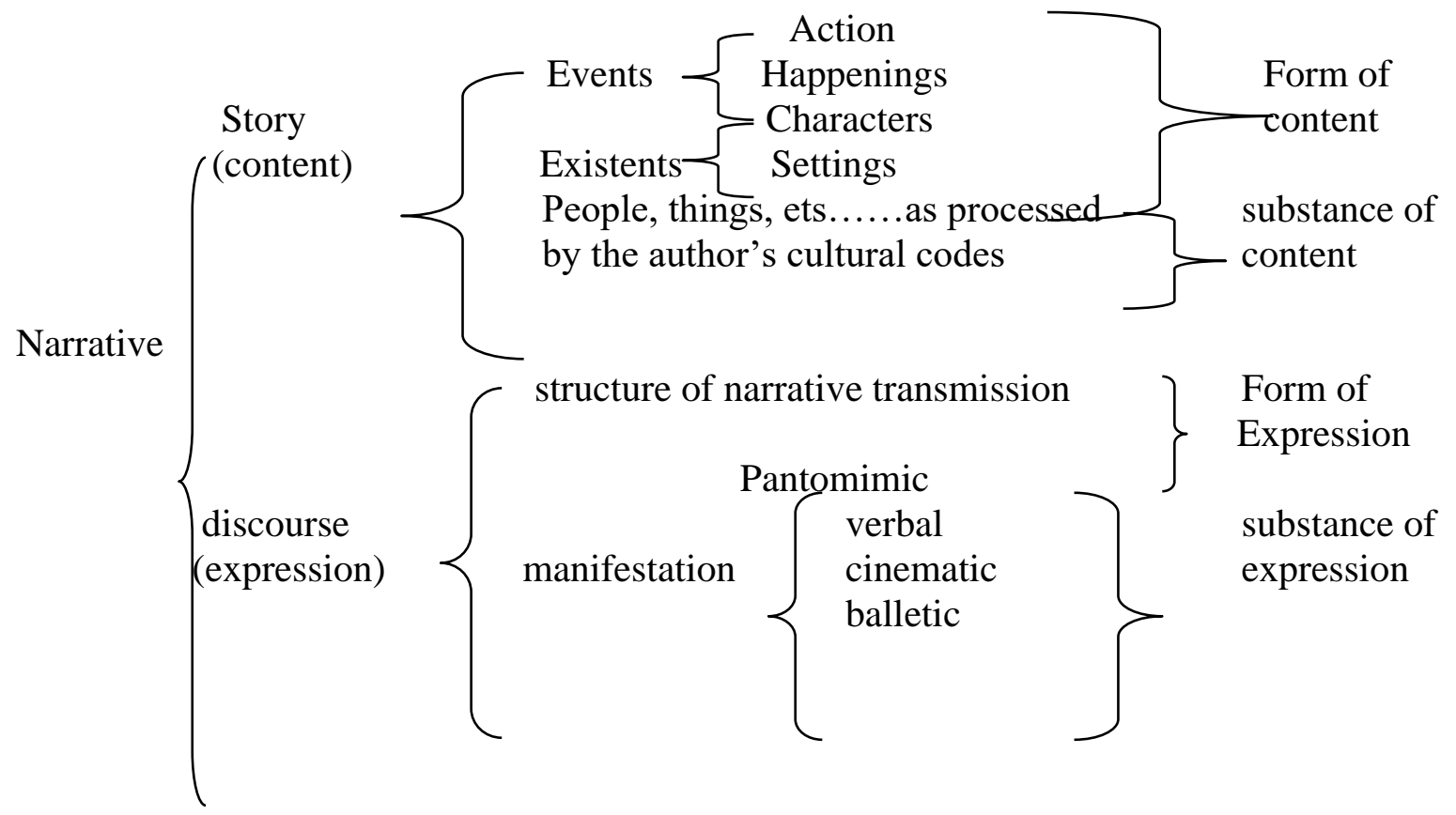

Figure 1. Outline of narrative components (Chatman, 1978, p. 26)

The diagram above illustrates the sustained analysis of fiction given by Structuralists, who majored in narrative understanding. Centuries of findings in the literary corpora have enriched the repertoire of tools that were available to the cognitive analyst, undoubtedly. However, the question of its distinction as a science of reading and interpreting narratives remains skeptical. Structuralism as a paradigm is equated with the term Narratology; most critics refer to it as Structuralist Narratology. After the cognitive turn in recent decades, however, it became known as classical Narratology (Bortolussi \& Dixon, 2003; Fludernik, 2005; Jahn, 1997). More recent 
attempts at rendering narrative fiction relevant to the complexities of the reader and the reading process were discussed by Herman (2005); Rimmon-Kenan (2002); Bal (1997); Fludernick (2005), among others.

From a historical perspective, Jahn (1997) first used the term Cognitive Narratology in a dually published conference article with Ansgar Nunning. Cognitive Science brought furnishing accounts to the pre-existing findings. The Structuralist Barthes (1977) pinpointed interest in the reader he claims that:

"Actions (terms of the proairetic code) can fall into various sequences which should be indicated merely by listing them, since the proairetic sequence is never .more than the result of an artifice of reading: who ever reads the text amasses certain data under some generic titles for actions (stroll, murder, rendezvous.)..." (transl. Miller, 1997)

Furthermore, the findings in Cognitive Psychology spread out of an interest in the reading process per se. They combined the three essential parts involved in a narrative to study how the reader creates the text world. In what follows, a detailed analysis of the TWT developed by Gavins (2007) is explained. In a similar vein, two main trends emerged along with the recent cognitive turn in Narratology, Cognitive Narratology, and Cognitive Psychonarratology. Jahn (1997) and Herman (2010) used the former, whereas Bortolussi and Dixon (2003) majored in the latter as two complementary approaches to the cognitive study of narrative. As its name indicates, Psychonarratology is concerned with the individual, i.e., his construction of narrative understanding. Building their findings on prior Reader-Response Theory and Catherine Emmott's (1997) depiction of the reader as an active agent in the reading process, Bortolussi and Dixon (2003) supported the intermingling of Cognitive Psychology and Literary Studies. For them, the divergent stages that readers go through in reading a narrative or constructing it on their own can be better studied empirically through cognitive psychological insights. Their main objectives were twofold: first, to "set a theoretical treatment of the reading process which must be precise and accurate; second, to examine the predictions made empirically by observing the response of actual readers" (Bortolussi \& Dixon, 2003, p. 13).

Although the study of Narratology from the seventies through the eighties consisted of many approaches to arrive at an accurate interpretation of literary texts, Narratologists failed to describe the intrinsic mechanisms active during the reading process. The works of Chafé (1994), Tannen (1982-1984), Potter and Whetherell (1987), White (1981), Ricoeur (1977) provided a background to the study of the reader's mind. How knowledge about the mind can be gained from narrative; how individuals behave in social and personal relationships; how they interact with the world around them; how they shape their experience of reality, and how cultural norms and codes affect them, are the sum of questions that the aforementioned researchers answered. (Bortolussi \& Dixon, 2003).

Unlike the previous conceptions of reading, Stockwell (2002) differentiated between the two acts of reading literature, reading, and interpretation. He defines each as follows: 
Interpretation is the recognition of the literary text in its entirety, a holistic understanding of a literary work that begins in our culture even before we begin to read the actual text, when the experience is ongoing and as yet unexpressed. [...] when readers become aware of what they are doing, this more analytical stage of recognition is 'reading'. (pp. 30-32)

Apart from differentiating between the two intersecting stages of reading narratives, as stated above, the cognitive approach to analyzing fiction fails to show a clear-cut line between interpretation and reading. Furthermore, how can the transition from one stage to the other be salient? As answers to these queries, Stockwell (2002) adjusted the triangle of narrative reading to the three main agents, real reader, real author, and text.

\section{Real author

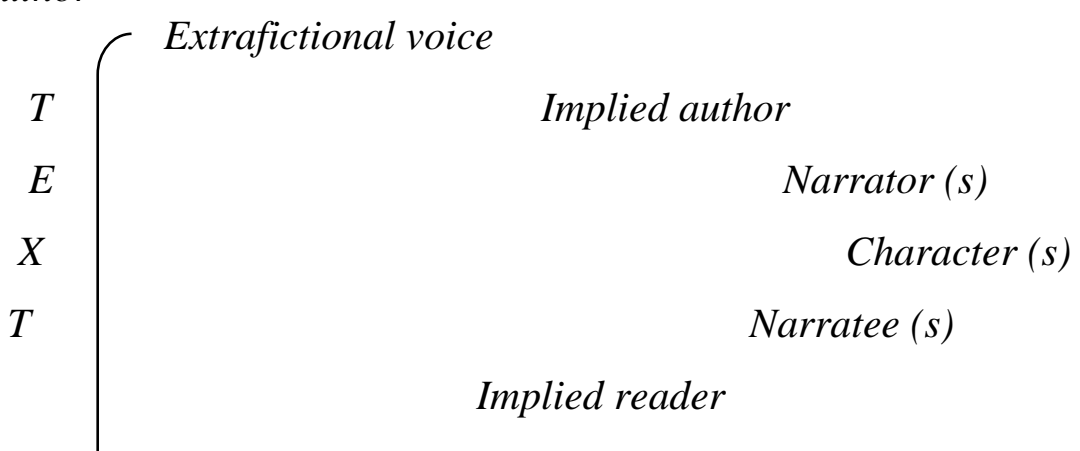 \\ Idealized reader}

Real reader

Figure 2.The Triangle of Narrative Reading (adapted from Stockwell 2002: 42)

It is essential to mention that the diagram sketched out above sprang out of the Deictic Shift Theory, which pertains to the cognitive poetic analysis of texts. MST, Schema Theory, Possible Worlds Theory, and DWT are among the approaches discussed under the cognitive poetic analysis that Stockwell (2002) provided. An amalgamation of the techniques can be used, and a specific selection of the appropriate method to texts.

\section{Text World Theory}

So far, the cognitive paradigm shift in the study of fiction was explained to provide the basis for the analysis of the case study in this paper, Life is Elsewhere (1973) by Milan Kundera. It should be emphasized, though, that the cognitive turn brought multiple levels of analysis into the literary aura. Since the present work is concerned with both thematic and structural linguistic analysis, selection fell on TWT. 
TWT seems to have been anticipated by the incomplete work of Werth (1999) on which Gavins (2007) built her theory. After observing the discrepancies that Stylistic and Structuralist linguists ended up with, Werth proposed a unified theory that would assimilate discourse analysis with a stylistic linguistic approach to textual analysis. Its ideas bring to the fore the cognitive linguistic concepts, mental space, metaphor, frame, and metonymy into contact with a theory of text and discourse as a whole. This latter fact makes the newly introduced study of literature an amalgam of text and context. Werth (1999) reinforces his theoretical proposal by defining it as "a theory of language genuinely relating the domain of cognition and language in a practical way that respects what we know about each domain" (p. XI).

Particular to Werth's theory of discourse and his predecessor Semino (1997), on the importance of the sender and the recipient is the dynamic process that text and context offers. They both agree that the notion of text world is based on the conceptual space, which sender and receiver construct when interacting with texts. Werth (1999), additionally, proves that a better interpretation of texts should be inclusive of cognitive spaces. He states:

All of semantics and pragmatics operates within a set of stacked cognitive spaces, termed 'mental worlds' and that uses for language presuppose occurrence in a context of situation, and on top of that they also presuppose the existence of a conceptual domain of understanding jointly constructed by the producer and the recipient (s). (p. 17)

Werth set the ground for the subsequent work on text world analysis; it is worth considering his definitional notions of deictic spaces, incrementation accommodation, and sub-worlds. Werth's interest in discourse and text is informed by Pragmatics and Linguistics under a cognitive framework. In the first place, he insists on the Common Ground that underpins the readers' mental capacities at creating a mental world of interaction to achieve coherence. This cognitive discoursal operation is performed through our endowed ability to frame knowledge. Although Lakoff (1987), Langacker (1987), and Fauconnier (1985) had elaborated this cognitive explanation, his contribution criticizes their neglect of knowledge structures and discourse context (Hidalgo, 2000).

About the notion of deixis, as opposed to a traditional linguistic explanation of the term, Cognitive Linguistic research places equal importance on the experiential basis of language in cognition. Instead of labeling time and space of the speech situation between two interactants, the cognitive-linguistic paradigm concentrates on how this is achieved by the participants both linguistically and cognitively. Werth (1999) and Semino (1997) were criticized for their lack of reference to vivid experiences. Gavins' (2007) book, in contrast, offers examples in a compilation of chapters, which end with a further reading and a further investigation section for researchers and students in the field.

Deictic spaces, in Werth's theory of the text world, "are worlds that are delimited by a set of Spatio-temporal parameters and that are peopled by entities that enter different types of relations among them" (Hidalgo, 2000, p.323). More particularly, the text worlds that participants reach in interpreting texts to follow certain criteria that manifest their embodied, socio-cultural, 
and linguistic aspects. Since all cognitive-based studies of language demonstrate the intricate relationship between mind and body, Werth (1999) and later Gavins (2007) build their claims on rule-governed worlds that correlate with our actual everyday world.

Furthermore, the process that is mentioned above is dependent on two important facets of information decoding and encoding, incrementation, and accommodation. First, Werth (1999) denotes as one of the functions of language since it has an "informational function and a modality function". The former includes "propositional meaning", which in turn consists of "path expressions and modifications. Path expressions occur when an entity is connected to another, whereas modifications" manifest when "an entity is connected to a property" (pp. 157-196). Based on the assumption that the Common Ground is pivotal to text worldbuilding, "incrementation" concerns the propositional are incorporated and processed into this Common Ground in discourse to reach text coherence. For Gavins (2007), "incrementation is the private to public transfer of knowledge" and is the most important step of her theory of the text world.

In addition to the incorporation and processing of information, accommodation relies on the unconventional presentation of information using constituents other than the assertion component of propositions like embedded clauses and Noun Phrases. That is, what has been traditionally conceived as an implicit assertion that can be made salient through negation is no longer a phenomenon of discourse. The difference between a conventional assertion and accommodation, for Werth (1999), lies in the fact that semantic presuppositions are processed as known information or as an unconventional assertion that springs new information. All of the distinctions made so far are part of Werth's model of text world analysis. Other extensive details are beyond the scope of this research since our study is inspired by Gavins' (2007) and Stockwell's (2002) refined versions of the TWT.

The applications of the text world model were first limited to poetic texts; however, it was concluded that it is much more appropriate to the study of narrative fiction. The latter offers a broader scope of analysis as it employs a multitude of participants in the reading process, besides its linguistic rhetorical richness. It has been mentioned earlier in this section that text worlds are mental spaces; they involve the dynamic interaction between author, text, and reader. The link between each element can be studied through the linguistic ICMs and the deictic shifts that are present in work. All of this can be achieved through careful observation and analysis of the work of fiction. Discourse deixis is central to accomplishing the critical analysis accordingly.

Reference words such as the former and the latter; besides this, that, here, and there in a text are part of discourse on a broader level. These deictic discourse words, as Yang (2011) stipulates, are related to the speaker's current location in the discourse. They locate discourse in time and space, along with its encoding and decoding portions. He gives as examples: "I bet you haven't heard this joke; that was the funniest story I've ever heard; there is a nice point to discuss in class; here is a powerful argument" (p. 129). After explaining the importance of deixis to any

Arab World English Journal for Translation \& Literary Studies 
cognitive analysis of literature, it is important to demonstrate its applications, strengths, and weaknesses under text world analytical approaches.

It should be noted that TWT contains the following subdivisions, DW, TW, and the subworlds (Stockwell, 2002). The discourse world, as its name indicates, rests on the discourse that is created through communication where two participants are involved. The notion of context is crucial to the discussion of discourse worlds. Stockwell (2002) extensively examines the discourse world that is created as readers interact with texts. Discourse world is "the imaginary world that is conjured up by the reading of a text, and it is used to understand and keep track of events and elements in that world" (p.94). To achieve this, Stockwell (2002), hypothesizes that there must be a facility of transferring and linking the world created by the author with that of the reader. He calls such a condition as the "trans-world identity" (p. 94).

Though the distinction that was made by Werth (1999) might seem simple, it involves multiple unyielding results that could have been given by other Structuralist analysis. Semino (2007) provides a triangular approach to the analysis of a poem by Duffy. She combines Fauconniers' (1997) theory of Mental Spaces, Werth's (1999) TWT, and Emmott's (1997) Contextual Frame Theory to provide an accurate contextual analysis of Mrs. Midas. Semino (2007) concludes that "a text world analysis needs to be combined with detailed stylistic analysis, to account more fully for the meaning potential of texts" (p. 95). In other words, although a cognitive poetic analysis of fiction succeeds, to some extent, to highlight the meaning potential of blended worlds and mental constructions; it still needs a reference to its preceding Structuralist analysis from which Stylistics originated. Additionally, Semino (2007) pinpoints the centrality of character minds' accurate analysis, which is crucial to any interpretive account of fiction. Accordingly, Fludernik (1996, p. 30) argues:

"Experientiality in narrative as reflected in narrativity can [ ] be said to combine a number of cognitively relevant factors, most importantly those of the presence of a human protagonist and her experience of events as they impinge on her situation and activities. [ ] Since humans are conscious human beings, (narrative) experientiality always impliesand sometimes emphatically foregrounds - the protagonist's consciousness". (qtd in Semino, 2007, p. 67)

While Semino (2007) calls for a refined approach to text worlds through reference to Stylistics; besides her limited proposal to short narrative texts, Stockwell (2002) stipulates that "Text World Theory is founded not on the analysis of sentences, but on entire texts and the world they create in the minds of readers" (137). Gavins (2007), further, prioritizes TWT over other discourse theories, and even over CL through the notion of incrementation. She provides a host of terms inspired by Cognitive Linguistic research to offer a better understanding of literary excerpts, newspaper articles, everyday communicative situations, and even obituaries.

Despite its theoretical and linguistic richness, the text world perspective to literary research, under Gavins' foci, still needs further details on how texts mean? Kohn (2011) criticizes 
Gavins' (2007) emphasis on the construction of mental models, which in turn undermines how "ideological content is created in the mind of the reader. He goes on to say that "culture, embodiment, and experiences are informants of the reading process, and they provide hermeneutical systems of meaning (27)" that Gavins' (2007) seems to undervalue (qtd. in Kohn, 2011 , p. 4). Further, critical views of the text world perspective came out of the need to combine characters' idiosyncratic or mistaken worldviews such as Lok in Goldings' Inheritors or Bromden in One Flew over the Cuckoo's Nest. Ryan (1991) shifts to both characters' and narrators' actual worlds that are difficult to access through text world analysis (Semino in Kristeniansen; Achard; Dirven \& De Mandoza, 2009).

Before delving into the analysis of character minds that MST is built upon, consideration of the practical analysis of the text world is schematized in the lines to follow. For reasons of basic generalizations of the theory that can be applied to any narrative excerpt, Stockwell's (2002) is provided rather than other contextualized schemas. Although Werth (1999) first introduced the two dichotomies that form the basis for every text world analysis, some refinements are worth consideration in Stockwell's (2002) version. Two mechanisms are used by participants to construct a text world, world-building elements, and function-advancing propositions. The former constitutes

"an orientation in time and place, and they create characters and objects which furnish the text world available for reference. The latter, however, include states, actions, events and processes, and any arguments or predications made in relation to the objects and characters in the text world". (Stockwell, 2002, p. 37)

Important of which is the illustrious example that Stockwell (2002) gives. His detailed analysis of a passage from The Voyage of the Dawn Treader (1952) by C.S. Lewis combines Halliday's material and the mental processes with his function advancing elements and world builders. He then stresses the importance of familiarity with the story through prior readings or reading of the other works by the same author. In sum, building the correct text world, which complies with, that of the author entails a narrow reading; hence, it is restricted to a few. This major finding restricts the scope of interpretation since people possess varying capacities of referencing. A non-native reader coming from a culture that conceives things differently would grapple with such a finding. A way of resolution to this emblematic query is the redefinition of one's culture in a modern world. In lieu of reference, Gavins (2007) adjusts the traditional definition of culture to what follows:

"(...) our sense of culture is influenced by far more than just where we were born. It is not simply the accumulation of experiential knowledge structures as a result of interaction with the world. It is, more importantly, how we individuals make connections between those separate knowledge structures in order to define ourselves in relation to others, and how others define us in return”. (p. 23)

For Gavins (2007), interaction with the surrounding, including the body, the mind, and culture in the current context, helps furnish text worlds in fiction. Stockwell (2002), additionally, sees this 
capacity to generate a world of the text, at hand, or in other types of communication as innovative as it brings to the fore pre-knowledge into contact with text and context in a cognitive frame. Methodology wise, Stockwell (2002) labels world-builders as (t) time, (1) location, (c) characters, and (o) for objects. Function-advancers, on the other hand, are recoverable from various patterns as unfolds underneath:

Table 1. World-builders and function advancers

$\begin{array}{lllc}\begin{array}{l}\text { Text type } \\ \text { Narrative } \\ \text { Descriptive: }\end{array} & \begin{array}{l}\text { Predicate type } \\ \text { action, event }\end{array} & \begin{array}{c}\text { Function } \\ \text { plot advancing }\end{array} & \begin{array}{c}\text { Speech act } \\ \text { report, recount }\end{array} \\ \begin{array}{llc}\text { Scene } \\ \text { person }\end{array} & \text { state } & \text { scene-advancing } & \text { describe scene } \\ \text { routine } & \text { hate, attribute } & \text { person-advancing } & \text { describe character } \\ \text { Discursive } & \text { relational } & \text { routine-advancing } & \text { describe routine } \\ \text { Instructive } & \text { imperative } & \text { argument-advancing } & \text { postulate, conclude... } \\ \text { goal-advancing } & \text { request, command... }\end{array}$
and so on.

Note 1. Adapted from Stockwell (2002, p. 137)

\section{Methods}

Milan Kundera is well known for his controversial and conflicting ideas as ambiguously revealed in the lives of the characters of his novels; however, the same interpretations have been deduced anonymously. The available literature about the style and criticism of his works resorts the confusion that results from reading interpreted novels to the lack of clarity that the latter reverberates. Many passages have been misinterpreted; chapters reordered, and even cultural codes miss-interpreted to list a few of the shortcomings of translating Kundera's novels. It might be true, to a certain degree that our choice of the English version of his two novels leaves out some of their originality unrevealed. Nevertheless, the approach used under the Cognitive Poetic framework could objectively cater to both formalist and contextual aspects of the works as aesthetic ideals and highly Universalist novels. Kundera's novels mattered for the reader simply because they choreographed life experiences of individuals who share the same instincts, but his philosophy of self, love, and history gauge questions as to whether his readers are aware of each over the other. Do readers conceptualize the worlds and sub-worlds of each novel as every possible hermeneuticsproponent critic would want them? Cognitive Poetics, as a science of reading and interpreting literature, does just that by offering the means of literary analysis that would facilitate reception and interpretation of novels and any other sort of rhetoric.

Theme wise, the present research explored the socio-political orientations of the novel Life Is Elsewhere (1973). Though a cognitively inspired approach might seem odd at the thematic level, for a purely hermeneutic researcher, the level at which both author and reader would exchange meaning from the texts is catered for in the rich textual world of the novel. It has been demonstrated that the abstract nature of the Kunderean novel would be better analyzed via its adjacent abstract cognitively oriented discipline. Both the outside inwards and the inside outwards approaches are accounted for in the analytical part of the paper. 


\section{Findings}

\section{Cognitive Poetic Analysis of Life Is Elsewhere}

According to MacDonals (2001), Kundera's novel is better understood by applying the new way of thinking strategy. His proposal transcends the thematic level to the strategic role of the narrator. He stipulates that "the primary object of criticism is not the story, but what is proposed by any story, the narrator" (qtd.in Jahn, 1997,p.11) He further adds that the best way to study novels under the umbrella term, the new way of thinking, is to conduct a formative study under the Free Indirect Discourse method. For reasons of clarity, though the proposed method is close to the cognitive stylistic reading of Life Is Elsewhere (1973), the FID is explained underneath:

"Free Indirect Discourse - a technique for rendering character's speech of thought. FID does this indirectly in the sense that it transposes pronouns and tenses into the pronoun/tense system of the narratives ordinary sentences (for instance, it may shift a first person into a third person, and a present tense into the past). As a consequence, there is often no formal difference between FID and a plain narratorial statement”. (Jahn, 1997, p. 11)

It follows from the passage above that the newly introduced technique of narrative analysis accounts for the form and function of narratives. Cognitive stylistics, indeed, has its share in the narrow reading of narratives. Undertaking a structural perspective and adding a cognitive dimension, Herman (2009) proposes a cognitive linguistic framework and extends focalization to conceptualization and construal. In the stylistic tradition, focalization refers to the perspective of narration, the viewer, or the speaker of the narrative. However, the concept itself remains detailed, offering a clear-cut method to delineate the angles of the story. It should not be confused with point of view since it is richer and narrow in perspective. Gennette (1980) defines focalization as:

"Focalization is a way of talking about perceptual and conceptual frames, more or less inclusive or restricted, through which participants, situations, and events are presented in a narrative. Thus, in what Gennett calls internal focalization, the viewpoint is restricted to a particular observer or reflector, whereas in what he calls zero focalization, the viewpoint is not anchored in a localized position". (qtd in Brone \& Vendaeel 2009, p.101)

It has been clarified that the readings of the novel are cognitive poetic in nature. Some researchers coin the study as cognitive poetic, while others prefer Cognitive Stylistics. Cognitive Narratology is about cognitive stylistic readings. Herman (2009) provided the fundamental standpoint between the two disciplines to study narratives. Conceptualization and construal are refurnished versions of focalization and perspective, but their application remains restricted to researchers who are well versed in the cognitive linguistic domain. Kundera's fascination with variation and oppositions make his narratives rich and complex. In Life Is Elsewhere (1973), he mixes multiple techniques in choreographing the life of the young poet Jaromil; His narrator is domineering at times, but the details he provides are intrinsically based on Kundera's existential philosophy.

Arab World English Journal for Translation \& Literary Studies 
In reference to the formalist classification of narrative, the novel is a third-person narrative in which a narrator who knows what characters do, think, and feel tells the story. A detailed description of the character of Jaromil and his mother, besides the lives of the other poets, makes the reader question the genre of the novel itself. Is it a biography of the poet Jaromil or an aesthetic critic of the Bildungsroman? What makes the novel existential and satirical at the same time? When asked about the intention behind writing the novel, Kundera (1990) answered:

And so you have written a lampoon of poetry? Not at all! Not a lampoon but a satire. There is no exaggeration in my novel. It is much more an attempt to undertake by means of the novel, a phenomenological description of the lyrical attitude, the lyrical conception of the world. (qtd in Harper, 1990, p.74)

Herman's proposition of the cognitive dimension in determining focalization as a process of conceptualization provides details to analyze Kundera's narrative techniques. The novel in question can be divided into three narrative techniques, the oneiric style in the second chapter and the digressive narrative voice in the whole story (Herman,2009). From a cognitive perspective, focalization is central to the determination of who sees, speaks, and conceptualizes at the same time. Based on the embodiment people are endowed with, Herman (2009) explains that the same situation can be interpreted and presented in different ways. His version of the cognitive analysis of narrative, however, appeals for the supporters of narrow reading informed by cognitive and stylistic advancements. Before delving into the analysis of the novel, Herman's redefinition of focalization should be first introduced. "The basic idea behind conceptualization or construal, to him, is that the one and the same situation or event can be linguistically encoded in different ways, by means of locutions that are truth-conditionally equivalent despite more or less noticeably different formats". (qtd in Brone \& Vendaeel, 2009, p. 103 )

The starting point that can be drawn from the novel is that the whole novel is about the story of Jaromil and his mother. The focalizer or narrator in the general sense is introducing the stories of Maman's life like a bourgeois girl and an adventurous young woman in the first chapter, her possessive nature, and its effects on the young Jaromil. The narrator holds a position that alternates between the spatiotemporally narrow perspectives to the wider scope image of life as the author understands it. Throughout the novel, the narrator intervenes to comment on the actions and the behaviors of his characters, but the perspectives that originate from the conceptual system of the whole narration vary according to the chapters and the situations. By way of example, three passages from the novel are analyzed following Herman's framework.

They whistled and demanded the floor to answer him. After a while Jaromil rose to his feet, too. His eyes were filled with rage, and the croud was at his back. He said that only the revolution was modern whereas the decadent eroticism and unintelligible images of surrealist art were junk that had no connection with the people. 'What is truly modern?' he challenged the famous poet. Your obscure lines, or we who are building a new world?' He answered his own question: 'There is nothing absolutely modern in the world except the 
masses of the people, building socialism.' Thunderous applause greeted his words. (Kundera, 1973, p.161)

The old radio crackled as Gottwald's words were drowned out by the thunderous acclaim of the croud. All this excited and enthused Jaromil, who was standing in his pajamas in Grandma's room, his neck all bandaged up, shouting hoarsely: At last! It had to come! At last!' (...) He told himself that the crowd gathered in the square had hurled today's date high into the sky where it would shine like a star for centuries. And it occurred to him what a shame it was that on such a glorious day he was stuck at home with Grandma rather than being out in the streets with the people. But before he had time to think this idea through, the door burst open and his uncle appeared, flushed and excited, shouting: 'you hear what's going on? (Kundera, 1073, p. 118)

By systematically studying construal in narratives, Herman (2009) digs deeper into perspective to determine how construal and language are shaped to reveal narratives. The degree of granularity or detail is given in the text, static or dynamic representation of scenes, and viewpoints on scenes whether distal, proximal, or medial are sub-components that previous theories neglected. In the quoted passages above, focalization is external and internal, according to the Gennettian theory. Jaromil's actions and inner feelings are described from a distant observing eye. In the first passage, the conceptual perspective is static rather than dynamic. It is situated at a medial distance from the regarded scene. It follows from that description that the construal is medial in scope.

In the second passage, the conceptual system involved in narration is narrower in scope than the first passage. Jaromil's feelings and expectations about the revolution are revealed in detail. That is, the level of granularity is proximal. The same detail is provided whenever Jaromil experiences a situation of blushing, redness, excitement in life, love, and revolution. It is one of the techniques of a conceptual narrative structuring system. Selection and foregrounding certain elements over others are among the tools of narration. Kundera's narrator continuously portrays Jaromil as the young child, who never grows to maturity, his character is static in terms of maturity; however, his narrative construal is varied. The latter classifies Kundera's works as aesthetic ideals.

In the same passage, cognitive narratologists analyze it as Jaromil's conceptual structuring system. That is, the perspective is seen from the character's standpoint. The focal participants in the conceptual system are Jaromil, Grandma, and his uncle. The scene described is about the feverish desire for a revolution that young Jaromil holds. The scene is sequentially scanned from the initial radio announcement to his argument with his uncle. The past tense indicative verbs used in the passage indicate that the scene has been sighted from a temporal viewpoint. The latter is situated at the same level as the represented actions the news, Jaromil's state, then his uncle's arrival. Spatially, the scene is represented from a viewpoint situated in the same plane as the represented action, in the first part; afterward, it changes to become different from the hypothetical situation that Jaromil sees outside in the streets. Initially, the viewpoint is distal offering little detail about the outside where streets are full of revolutionaries; it is limited to the radio. Then, 
Jaromil's actions are described from a proximal viewpoint. His position inside his Grandma's room in his pajamas enthused and excited offer a narrow-scope and highly granular situation.

Within the same passage, another conceptual system of conceptualization takes place. Jaromil creates a hypothetical scene based on the outside world that is witnessing revolutionary change after the radio announcement. It is marked by the shift to indirect thought that he evokes. 'He told himself' and 'it occurred to him' are used to transition perspective. Scope and granularity also vary. Only short details are given about the situation in the square; instead, he created another situation where the day is compared to the star shining in the skies for centuries. The perspective viewpoint is, henceforth, distal, and the degree of granularity is low. In the lines that follow, the narrative construal is shifted back to the first scene where Jaromil hurries to his uncle, denouncing his reaction towards the news. The detail is given, and the scope is medial. Throughout the novel, many construal conceptualizations occur, which make Kundera's novel an aesthetic ideal and a skillfully controlled narrative. For further illustration, the third passage is quoted and analyzed underneath.

He gazed at her, letting her last words reverberate in his mind. Yes, that's how it was. The whole time when he was tormented by loneliness, when he kept throwing himself desperately into meetings and parades, when he kept running on and on, his manhood had already been prepared for him, (...) this room and this commonplace woman whose body had finally created a physical bond between him and the people. (Kundera, 1973, p.169)

At the beginning of the passage, Jaromil's triumphant moments over solitude and his mother's possessive nature are described from a scope perspective as he converses with the girl. However, the viewpoint shifts with a confirmation statement, 'yes, that's how it was'. The perspective is wider in scope, which would allow the reader to see the whole picture of his journey towards maturity in life. The degree of granularity is less, but its significance is wider. The scene is sequentially scanned, and its initial participant is the girl. The past tense indicative verbs, again, indicate that the scene has been temporally seen. Spatially, indeed, the scene is represented from a viewpoint situated on the same level as the represented actions. Jaromil's actions take place in the same room. Another conceptual system is created in the last part of the passage; the transition to the detailed description of the room, which linked him to the world, is granular. The scope hence is proximal, narrow in scope, and highly granular.

So far, we have catered for the use of the cognitive framework offered by Herman in the study of narrative. The same or nearly equal systematicity will result if focalization theory offered by Stylisticians is applied. Another point at issue is whether the same framework would be used to analyze the second part of the novel. If the same perspective were used, it would yield equal analysis without the distinction between oneiric style and narrative digressions that former stylistic and formalist approaches provide. The novel is dense with narrative techniques that would allow structural, stylistic, and cognitive-inspired analyses. Life Is Elsewhere (1973) is a merit of narrative control in that the author allows the reader to live the life story of a young poet, to appreciate his ups and downs, at the same time, read his philosophic ideas about life and his artistic 
control of the novel. His narrator intervenes in every part to reveal his philosophical judgment of life, love, and history. The author comments on the artistic significance of the novel:

Already Life Is Elsewhere (...) is not situated exclusively in Prague. True, the protagonist is a native of Prague who never leaves the city. However, the novel's décor is larger than the décor of my protagonist's story. (...) my novel not only deals with events which took place in Prague, but with those in Paris in May 68'; It not only deals with Jaromil (...) but also with Rimbaud, Keats and Victor Hugo. To phrase it technically: the décor of the novel is enlarged by the narrator's digressions throughout Europe. Jaromil's décor is Prague, the novel's décor is Europe. (Elgrably (1987), qtd in Harper, 1990, p. 92)

\title{
Conclusion and Discussion
}

The works of any avid reader and a thorough developer of idiosyncratic philosophical ideas wrapped in an aesthetically ideal work would be puzzling to the reader. Reading Kundera's novels makes a call to reconsider life as his characters experience it. His textual universe is rich and varied, often philosophically ambiguous, but can be as plainly understood as any other work of the same complexity. The approach that has been undertaken in this research study is informed and structured following the cognitive poetic framework.

Narrative control or aesthetic ideal is an inquiry into the stylistic skill of the author. Life Is Elsewhere (1973) is a novel of themes and the life of a young poet, as stated previously. The author excels in the construction of a story inside the minds of the characters, that is told by an intelligent psychologically and thematically genius narrator. He uses multiple techniques in choreographing the life of the young poet Jaromil. His narrator is domineering at times, but the details he provides are intrinsically based on Kundera's existential philosophy. The focalizer is introducing the stories of Maman's life as a bourgeois girl and an adventurous young woman in the first chapter, her possessive nature and its effects on the young Jaromil. The narrator holds a position that alternates between the spatiotemporally narrow perspectives to the wider scope image of life as the author understands it. Passages from the text have been analyzed to show the multiple levels of conceptualization that the author uses. What I tried to highlight is the particularity of his works. Like James Joyce, his style is a reflection of his skill at impinging his self against the others, and this is one of the reasons he detracts translations of his works. How he structures sentences and introduces concepts, how he rhythmically parallels life experiences vis-à-vis syntactic patterns, the abstract nature of his metaphors, and the witty challenge of the common-sense conception of eternal return are part of his God-like command over his novels.

\begin{abstract}
About the Author:
Dr. Sara Mechraoui is a recent Indiana University East Graduate (IUE); she earned the Graduate Certificate in Composition Studies in 2020. Sara got her Doctorate in English Literature in 2017 from Abou AlKacem SaadAllah University, Algiers, Algeria, in 2017. Her Master's concentration was English for Specific Purposes. She worked as an associate professor of English at the Teacher's Training College (ENSL), Laghouat, Algeria, for three years.

ORCID ID: https://orcid.org/0000-0002-6843-2155
\end{abstract}

Arab World English Journal for Translation \& Literary Studies 
AWEJ for Translation \& Literary Studies Volume, 4 Number 4. October 2020

Narrative Control or Aesthetic Ideal: Cognitive Narrative Reading of Milan Kundera's

Mechraoui

\section{References}

Bal, M. (1997). Narratology Introduction to the Theory of Narrative (2 ${ }^{\text {nd }}$ ed.). Toronto and London: University of Toronto Press.

Barthes, R. (1977). S/Z (R. Miller, trans1.). New York: Farrar, Straus and Giroux.

Bernaerts, L, de Geest, D ; Herman, L \& Vervaeck, B. (2013). Stories and Minds: Cognitive Approaches to Literary Narrative. Lincoln : University of Nebraska Press.

Bortolussi, M., \& Dixon, P. (2003). Psychonarratology: Foundations for the Empirical Study of Literary Response. Cambridge: Cambridge University Press.

Brone, G., \& Vandaele, J. (2009). Cognitive Poetics: Goals, Gains and Gaps: Applications of Cognitive Linguistics. Berlin: Mouton de Gruyter.

Chafe, W. (1994). Discourse, consciousness and time: the flow and displacement of conscious experience in speaking and writing. Chicago: University of Chicago Press.

Chatman, S. (1978). Story and Discourse Narrative Structure in fiction and film. Ithaca and London: Cornell University Press.

Cook, G. (1994) Discourse and Literature. Oxford: Oxford University Press.

Emmott, C. (1997). Narrative Comprehension A Discourse Perspective. Oxford, USA: Oxford University Press.

Fauconnier, G., \& Turner, M. (2002). The Way we think: Conceptual binding and the mind's hidden complexities. New York, USA: Basic Books.

Fludernik, M. (1996). Towards a 'Natural' Narratology. London: Routledge.

Gavins, J. (2007). Text World Theory: An introduction. Edinburgh: Edinburgh University Press.

Genette, G. (1980). Narrative Discourse: An Essay in Method, (J. E. Lewin, trans.). Ithaca: Cornell University Press.

Harper, M. (1990). The role of the narrator in the novels of Milan Kundera, (Published Master of Arts Thesis). Texas Tech University, Texas, USA.

Herman, D. (2002). Story Logic: Problems and Possibilities of Narrative. Lincoln: University of Nebraska Press.

Hrushovski, B. (1976). Segmentation and Motivation in the Text Continuum of Literary Prose: The First Episode of War and Peace. Papers on Poetics and Semiotics, (5). Tel Aviv University.

Jahn, M. (1997). Frames, Preferences, and the Reading of Third-Person Narratives: Towards a Cognitive Narratology. Poetics Today, 18(4), 441-67. DOI: 10.2307/1773182

Kohn, N. W. (2011). Collaborative fixation: Effects of others' ideas on brainstorming. Applied Cognitive Psychology, 25(3), 359-371.

Kristeniansen, G., Achard, M., Dirven, R., \& De Mandoza, I. , F. (2009). Applications of cognitive linguistics. Berlin, New York: Mouton de Gruyter.

Kundera, M. (1973). Life Is Elsewhere. New York: Alfred A. Knopf, Inc.

Kundera, M. (1984). The Unbearable Lightness of Being. New York: Harper \& Row Publishers Inc.

Arab World English Journal for Translation \& Literary Studies 
Lakoff, G. (1987). Women, fire, and dangerous things. Chicago: The University of Chicago Press. Langacker, R. (1987). Foundations of Cognitive Grammar, Vol. I: Theoretical Prerequisites. Stanford, CA: Stanford University Press.

Mandler, J.M. (1984). Scripts, Stories and Scenes: Aspects of a Schema Theory, Hillsdale, NJ: Lawrence Erlbaum.

Palmer, A. (2004). Fictional Minds. Lincoln: University of Nebraska Press.

Potter, J. \& Whetherell, M. (1987). Discourse and social psychology: Beyond attitude and behavior. London: Paul Chapman Publication Ltd.

Ricoeur, P. (1977). The Rule of Metaphor: Multidisciplinary Studies of the Creation of Meaning in Language (R. Czerny, trans.). Toronto: University of Toronto Press.

Rimmon-Kenan, S. (2002)- Narrative fiction. London and New York: Routledge.

Ryan, M.L. (1991). Possible Worlds: Artificial Intelligence and Narrative Theory. Bloomington and Indianapolis, IN: Indiana University Press.

Schank, R.C. \& Abelson, R. (1977). Scripts, Plans, Goals and Understanding. Hillsdale, NJ: Lawrence Erlbaum.

Semino, E. (1997). Language and World Creation in Poems and Other Texts. London: Longman.

Sternberg, M. (2003) Universals of narrative and their cognitivist fortunes (I). Poetics Today 24(2), 297-395.

Stockwell, P. (2002). Cognitive Poetics: An Introduction. London and New York: Routledge.

Stockwell, P. (2005). Stylistics and Cognitive poetics. In H. Veivo, B. Peterson, \& M. Bolvinan (eds.), Cognition and literary interpretation in practice (pp. ?) Helsinki: University of Helsinki Press.

Stockwell, P. (2009). Texture: a cognitive aesthetics of reading. Edinburgh: Edinburgh University Press.

Tannen, D. (1984). What's in a frame? Surface evidence for underlying expectations. In R.O.

Freedle, (ed.), New Directions in Discourse Processing, (pp. 137-81). Norwood, NJ: Ablex.

Werth, P. (1999). Text Worlds: Representing Conceptual Space in Discourse. Harlow: Longman.

White, A. (1981). The Uses of Obscurity: The Fiction of Early Modernism. London: Routledge \& Kegan Paul.

Yang, Y. (2011). A cognitive interpretation of discourse deixis. Theory and Practice in Language Studies, 1(2), 128-135.

Appendix A

Summary of Life Is Elsewhere

Set after the Communists took over Czechoslovakia, the novel narrates the story of the poet Jaromil. His life from inception to his premature death is detailed, in a linear sequence of chapters. We learn of the poet's mother, Maman, as the daughter of a rich family. She gets pregnant from a young engineer, who refuses parenthood and asks her to abort the fetus. Her family, accordingly, forces him to marry her, and she gives her unborn baby prophetic importance. She resembles her devotion to the virgin Marry and her son to Apollo and named him Jaromil. Her over-protection 
and the fact that he has been raised in a female-dominated house made of him a spoiled fragile child. Unhappy with his situation, Jaromil befriends the Janitor's son and beats and tortures a young child badly. His father quits the family; Jaromil then grew up with an intensive admiration of male-related activities.

His mother took him to an artist who taught him Surrealist ideas. Before devoting his time to writing poetry, 13 years old Jaromil painted headless women and dog-people. We learn then of the love affair between the poet's mother and the artist who annoys her with his intellectual theories and his painting about her nude body. She eventually leaves the artist and concentrates on her son's poetic rhyming verses. Jaromil's attempt to grow from childhood to maturity came along with his longing for having sexual relationships with girls. He first fails to get along with his university mate. His second girlfriend is a red-headed girl who seemed experienced in having sex with other men the fact that later led to their break up.

Jaromil's revolutionary ideas came to the fore when the Communists took full control of Czechoslovakia. He excelled in writing rhyming and rhythmic poems that dealt with Communists' social and political ideals. Fascinated by the idea of power, Jaromil admires the Janitor's son, who tortures prisoners. The police chief officer invites him to a police poetry recitation, which Jaromil finds very revolutionary. After attending and participating in the poetry night, Jaromil and his friend were taken to a beautiful filmmaker's apartment to spend the night. He succeeds to have sex with the girl, but his behaviors prove futile for both of them. She claims that she was arranging her brother's escape from the country. Shortly afterward, Jaromil tells the police about their plot, and both the red-head and her brother were arrested. The narrator, then, devotes a whole chapter to explaining the red-headed girl's relationship with another man after Jaromil's death, the same men whom she met before joining Jaromil that night.

In the last parts of the novel, Jaromil is invited to the filmmaker's party, where he ventures to win her over, but his end approaches courting it like Lermontov. A fight between Jaromil and a man in the party followed verbal insults about Jaromil's plot against his friend, the artist, and he was thrown on a cold terrace. The young poet Jaromil catches pneumonia afterward and dies. 